\section{Über die Fällbarkeit von Entero-Viren mit Polyphosphorsäure}

\author{
W. A. K. Schmidt, H. Pittler und W. Höpken \\ Staatl. Medizinal-Untersuchungsamt in Hannover \\ (Direktor: Dr. med. habil. R. Wohlrab) \\ (Z. Naturforschg. 20 b, 402 [1965] ; eingegangen am 19. Dezember 1964)
}

Kürzlich berichteten wir ausführlich ${ }^{1,2}$ über eine Fällungsmethode, die es gestattet, Polio-Antigenbestandteile zu fraktionieren und große Antigenmengen zeitsparend und schonend zu konzentrieren. Als Fällungsmittel diente eine Polyphosphorsäure vom MG 〜 340 (Polyphosphorsäure techn., 83\% $\mathrm{P}_{2} \mathrm{O}_{5},\left(\mathrm{HPO}_{3}\right)_{\mathrm{n}}$, Fluka A. G., Schweiz). Die Konzentrations-Versuche wurden nun auch auf andere Typen der EnterovirusGruppe ausgedehnt. In der vorliegenden Mitteilung möchten wir darüber berichten.

Untersucht wurden Coxsackie-Virus B1 und B3, Echo-Virus Typ 6 und 11. Gleichzeitig wurde die Fällung von Polio Typ I zum Vergleich durchgeführt.

Die Vermehrung der Coxsackie- und Echo-Viren erfolgte in MS-Zellen, die der Polio-Viren in HeLa-Zellen. Als Erhaltungsmedium diente TCM 199. Die Infektiositäts-Bestimmungen gingen einheitlich in MSZellen vor sich. Jede Antigenfraktion wurde zweimal auf verschiedenen Zellchargen tritiert (8 Röhrchenkulturen pro Verdünnungsstufe).

Die für die Fällung vorgesehenen Roh-Antigenmengen (Gewebekultur-Überstand) wurden nach Abzentrifugieren des Zelldetritus (10 Min. $2200 \mathrm{~g}$ ) im Eisbad auf $p_{\mathrm{H}}$ 7,3 eingestellt, mit 0,5 mg Polyphosphorsäure pro ml Antigen versetzt und durch Zusatz verdünnter $\mathrm{HCl}$ auf $p_{\mathrm{H}} 3,5$ gebracht (die Polyphosphorsäure wurde als täglich neu bereitete 2-proz. wäßrige Lösung verwendet). Danach wurde 15 Min. im Kühlraum geschüttelt und dann das Sediment niedrigtourig abzentrifugiert (15 Min. $2200 \mathrm{~g}$ ). Das Sediment wurde in wenigen $\mathrm{ml}$ einer $\mathrm{NaCl}$-Lösung $(0,88-m$. $\mathrm{NaCl}+$ 0,04-m. $\mathrm{Na}_{2} \mathrm{HPO}_{4}$ mit $\mathrm{NaOH}$ auf $p_{\mathrm{H}}$ 9,0 eingestellt) aufgenommen und mit $1 / 3-n$. NaOH auf neutrale Werte gebracht. Der Überstand wurde ebenso auf $p_{\mathrm{H}}$ 7,0 eingestellt. Die Infektiosität des Ausgangsmaterials, des Überstandes und des Sediments wurde bestimmt. Tab. 1 zeigt die Versuchsergebnisse.

Die Infektiositäts-Ausbeute im Sediment war bei den Coxsackie-Virustypen B1 und B3 und bei Echo-Virus Typ 6 ebenso hoch wie beim Polio-Virus. Fast die gesamte Infektiosität lag im Sediment vor. Die Infektiosität des Überstandes betrug kaum 1\% der AusgangsInfektionsität. Beim Echo-Virus Typ 11 dagegen ließ sich noch etwa $1 / 10$ der Ausgangs-Infektiosität im

1 W. A. K. Schmidt, Zbl. Bateriol., Parasitenkunde, Infektionskrankh. Hyg., I. Abt., Orig. 191, 130 [1963].

\begin{tabular}{|c|c|c|c|c|}
\hline Virus & art und Fraktion & Menge & $\begin{array}{l}\text { Infek- } \\
\text { tiositäts- } \\
\text { titer }\end{array}$ & $\begin{array}{l}\text { Infek- } \\
\text { tiosität * }\end{array}$ \\
\hline$\stackrel{0}{\circ}$ & $\begin{array}{l}\text { Ausgangsmaterial } \\
\text { Überstand } \\
\text { Sediment } \\
\text { Ausgangsmaterial } \\
\text { Überstand } \\
\text { Sediment }\end{array}$ & $\begin{array}{l}30 \\
30,75 \\
3 * * \\
50 \\
51,25 \\
5\end{array}$ & $\begin{array}{l}10^{8,29} \\
10^{5,68} \\
10^{8,29} \\
10^{7,72} \\
10^{4,89} \\
10^{7,94}\end{array}$ & $\begin{array}{c}100 \\
<1 \\
100 \\
100 \\
<1 \\
161\end{array}$ \\
\hline 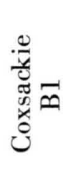 & $\begin{array}{l}\text { Ausgangsmaterial } \\
\text { Überstand } \\
\text { Sediment } \\
\text { Ausgangsmaterial } \\
\text { Überstand } \\
\text { Sediment }\end{array}$ & $\begin{array}{l}30 \\
30,75 \\
\quad 3 \\
300 \\
307,5 \\
\quad 6\end{array}$ & $\begin{array}{l}10^{7,74} \\
10^{5,88} \\
10^{7,81} \\
10^{8,46} \\
10^{6,33} \\
10^{8,35}\end{array}$ & $\begin{array}{r}100 \\
1 \\
118 \\
100 \\
<1 \\
78\end{array}$ \\
\hline 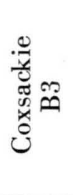 & $\begin{array}{l}\text { Ausgangsmaterial } \\
\text { Überstand } \\
\text { Sediment } \\
\text { Ausgangsmaterial } \\
\text { Überstand } \\
\text { Sediment }\end{array}$ & $\begin{array}{l}50 \\
51,25 \\
5 \\
300 \\
307,5 \\
\quad 6\end{array}$ & $\begin{array}{l}10^{6,21} \\
10^{3,72} \\
10^{6,35} \\
10^{6,32} \\
10^{4,26} \\
10^{6,46}\end{array}$ & $\begin{array}{r}100 \\
<1 \\
138 \\
100 \\
<1 \\
138\end{array}$ \\
\hline $\begin{array}{l}0 \\
0 \\
\stackrel{0}{0} \\
\text { I }\end{array}$ & $\begin{array}{l}\text { Ausgangsmaterial } \\
\text { Überstand } \\
\text { Sediment } \\
\text { Ausgangsmaterial } \\
\text { Überstand } \\
\text { Sediment }\end{array}$ & $\begin{array}{l}30 \\
30,75 \\
3 \\
300 \\
307,5 \\
\quad 6\end{array}$ & $\begin{array}{l}10^{5,77} \\
10^{3,67} \\
10^{5,73} \\
10^{6,73} \\
10^{4,89} \\
10^{6,67}\end{array}$ & $\begin{array}{r}100 \\
<1 \\
91 \\
100 \\
1 \\
87\end{array}$ \\
\hline 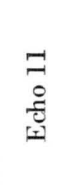 & $\begin{array}{l}\text { Ausgangsmaterial } \\
\text { Überstand } \\
\text { Sediment } \\
\text { Ausgangsmaterial } \\
\text { Überstand } \\
\text { Sediment }\end{array}$ & $\begin{array}{l}50 \\
51,25 \\
5 \\
110 \\
112,75 \\
11\end{array}$ & $\begin{array}{l}10^{6,89} \\
10^{5,81} \\
10^{6,77} \\
10^{7,59} \\
10^{6,67} \\
10^{7,63}\end{array}$ & $\begin{array}{r}100 \\
9 \\
77 \\
100 \\
12 \\
109\end{array}$ \\
\hline
\end{tabular}

Tab. 1. Infektiosität nach Fällung mit $0,5 \mathrm{mg}$ Polyphosphorsäure pro ml Antigen bei $p_{\mathrm{H}} 3,5$.

* Bezogen auf das Ausgangsmaterial. ** Zur InfektiositätsBestimmung wurde ein Teil des gelösten Sedimentes auf das entsprechende Volumen des Ausgangsmaterials gebracht.

Überstand nachweisen. Bei der großen $p_{\mathrm{H}}$-Abhängigkeit der Polyphosphatfällung ist es denkbar, daß die Präzipitation auch dieses Virustyps bei einem anderen, evtl. niedrigeren $p_{\mathrm{H}^{-}}$Wert als dem von 3,5 vollständig verläuft.

Die vorliegenden Ergebnisse lassen vermuten, daß eine Präzipitation durch Polyphosphorsäure auch bei den anderen, noch nicht untersuchten Entero-Virustypen möglich ist.

Frau E. Tiesler und Fräulein L. HartJe sei für ausgezeichnete technische Assistenz gedankt.

2 W. A. K. Sснмidt, Arch. ges. Virusforsch. 14, 508 [1964]. 